\title{
Profiles of learning opportunities of multilingual and monolingual children in kindergarten
}

\section{Annegien Langeloo ${ }^{1}$ (D) Mayra Mascareño Lara ${ }^{1}$ - Marjolein I. Deunk ${ }^{1}$. Jennifer LoCasale-Crouch ${ }^{2} \cdot$ Jan-Willem Strijbos $^{1}$}

Received: 17 December 2019 / Revised: 5 April 2020 / Accepted: 21 May 2020 /

Published online: 25 June 2020

(C) The Author(s) 2020

\begin{abstract}
Early childhood education serves an increasing number of multilingual children, and teachers are challenged to create high-quality learning opportunities in the classroom for all children. The child's engagement and interactions with the teacher are important in this respect. The present study therefore examined how multilingualism relates to engagement and teacher-child interactions, taking a person-oriented approach. During one school year, 76 kindergarteners (43 multilingual) from 19 classrooms were observed for behavioral engagement and individual teacher-child interactions. Five engagement profiles were identified that reflect different levels of engagement across classroom settings. Multilingual children were overrepresented in profiles that showed lower engagement in one or more settings. Also, five interaction profiles were identified that showed strong diversity in the interactions of teachers with children in their classroom. Monolingual and multilingual children were equally represented across these profiles. Children in the more beneficial interaction profiles were also often in the moderate-to-high engagement profiles.
\end{abstract}

Keywords Early childhood education · Multilingualism · Teacher-child interaction · Engagement - Profile analysis

\section{Introduction}

Children develop through interaction with the close environment (Bronfenbrenner and Morris 2007). In the school context, this means learning opportunities are created by interactions with peers and the teacher. Interactions between children and the teacher are of special interest due

Electronic supplementary material The online version of this article (https://doi.org/10.1007/s10212-02000487-0) contains supplementary material, which is available to authorized users.

Annegien Langeloo

aglangeloo@gmail.com

Extended author information available on the last page of the article 
to a teacher's pedagogical and educational role in classroom interactions, and their task to steer interactions with children, while keeping individual learning goals in mind. In effective learning opportunities, children are engaged (Fredricks et al. 2004) and have good-quality interactions that use both verbal and nonverbal channels (Goldin-Meadow 2000) to support extended, inferential talk (van Kleeck et al. 2006).

Early childhood education is increasingly faced with children that speak a different language at home than at school, resulting in new challenges to ensure their inclusion and learning opportunities in the classroom. Although comparison studies on the teacherchild interactions of monolingual and multilingual children are limited, a recent review study by Langeloo et al. (2019) suggests that multilingual children have different interactions with their teacher than monolingual children. Teachers use more nonverbal communication and less complex language when interacting with multilingual children, limiting the learning opportunities of multilingual children in interaction with the teacher. Furthermore, multilingual children might face problems to productively engage with the activities in the classroom, potentially because they have trouble following the cultural rules of the majority culture (Razfar and Rumenapp 2012). In the present study, we aim to better our understanding of the learning opportunities of children from diverse language backgrounds. To do this, we will examine the learning opportunities of multilingual and monolingual children by focusing on their teacher-child interactions and behavioral engagement. Moreover, we will focus on the teacher-child interactions that are unique for individual children, and on repeated observational measures of child engagement, in order to capture the situational nature of both teacher-child interactions and engagement.

\section{Teacher-child interactions}

The bioecological model of human development (Bronfenbrenner and Morris 2007) describes development as a result of the continuous interaction between the child's characteristics and the close context-the so-called proximal processes of development. In an educational setting, the interaction with the teacher is the main proximal process. A teacher is expected to adjust the teacher-child interactions - and with that the learning opportunities - of an individual child to his or her characteristics, so as to promote the child's academic development (Hamre and Pianta 2007). Three aspects to describe this adjustment of teacher-child interactions are the quantity of interactions with individual children, the language complexity of those interactions, and the communication channels used. A recent systematic review revealed that these aspects are critical in describing the interaction of teachers with monolingual and multilingual children (Langeloo 2019).

\section{Quantity of interaction}

Having opportunities to interact with the teacher is key for the development of young children (Childers and Tomasello, 2002; Christ et al. 2011). Differences in vocabulary size between children can, for an important part, be explained by the number of words they have heard in their early years (Hoff and Naigles, 2002; Weizman and Snow 2001). These studies suggest that a rich language environment in the classroom, with a high amount of teacher-child interaction, is important for creating high-quality learning opportunities. 


\section{Language complexity}

Talk about topics beyond the direct context-i.e., inferential talk, as opposed to literal talk, which refers to directly available information-is crucial for developing language skills (Massey et al. 2008). Inferential talk is more cognitively challenging than literal talk as it requires the child to make inferences - such as reasoning, predicting, and remembering - on available information (van Kleeck et al. 2006). The use of inferential talk has a positive influence on children's language skills, including comprehension, literacy, and vocabulary (De Temple 2001; Wasik and Bond, 2001; Wasik et al. 2006), and children are more likely to use inferential talk when their teacher uses it as well (Mascareño et al. 2017).

A related aspect of complexity are teacher follow-ups. Teachers can follow up on child responses with either an evaluative or an elaborative utterance. The evaluative utterance is limited to a simple evaluation (such as, "good job", "well done") or repetitive confirmations or falsifications of the child utterance, whereas elaborative follow-ups expand the conversation by elaborating on the child utterance or by giving a hint (Mascareño et al. 2016). Elaborative follow-ups carry the opportunity for extended discourse and are related to more child participation (Nassaji and Wells, 2000) and greater vocabulary development (Wasik et al. 2006). Teachers, however, are generally found to use mainly simple evaluative follow-ups, rather than the more complex elaborative follow-ups (Dickinson et al. 2003; Mascareño et al. 2016).

\section{Communication channel}

Teacher-child interactions can take the form of verbal utterances (i.e., the smallest units of speech that are often separated by a silence), but it often also includes symbolic gestures, and purely nonverbal communication. Nonverbal communication through symbolic gestures offers a child a simpler way to express and understand the interaction (Goldin-Meadow 2000), before they can verbally express it. When teachers use gestures, children can use this information as additional resources to understand the teacher talk (Roth 2001). The use of gestures in interactions with young children is known to support verbal language acquisition (Goodwyn and Acredolo 1998; Goodwyn et al. 2000) and is especially useful for children who have difficulty expressing themselves verbally (Daniels 1997). This could be children with lower language levels or children who are still learning the majority language.

All three components - i.e., quantity of interaction, language complexity, and communication channel-have been separately found to be important for high-quality teacher-child interactions. It is unclear, however, how these components relate to each other and contribute to the quality of teacher-child interactions.

\section{Behavioral engagement}

The potential contribution of teacher-child interactions to students' learning opportunities presupposes that children are able to focus and maintain their attention on the activity and interaction at hand. This implies that children are engaged (Fredricks et al. 2004; Laevers 1993). In kindergarten, there is a wide variety of activities and settings that demand different expressions of behavioral engagement. Previous studies on behavioral engagement in early childhood education indicate that children might show different levels of engagement in diverse classroom settings with or without the teacher, potentially affecting academic development. When children are involved in a free choice activity, they often show high 
engagement with the activity at hand, whereas in whole-class teacher-directed activities, children are more engaged with the teacher (Booren et al. 2012; Vitiello et al. 2012). Children that are primarily engaged in activities with the teacher show better school readiness than children that are primarily engaged in individual activities (Chien et al. 2010). Bratsch-Hines, Burchinal, Peisner-Feinberg, and Franco (2019) found that the time spent in large group settings was negatively associated with literacy development, potentially because teachers were less actively engaging children in the activity.

\section{Multilingual children: teacher-child interactions and engagement}

Multilingual children often enter and leave early childhood education with a smaller vocabulary in the language of instruction than monolingual children (Bialystok and Feng 2011; Verhoeven, 2000); they often come from a different cultural background than the majority culture and a lower socioeconomic background (Veenstra and Kuyper 2004). These differences between monolingual and multilingual children in their developmental trajectories and cultural background, in combination with possible teacher bias (Tenenbaum and Ruck 2007), might lead multilingual children to be involved in suboptimal learning opportunities in the classroom. Being exposed to good-quality interactions can be safely assumed to be beneficial both for monolingual and multilingual children. However, multilingual children seem to have more infrequent interaction with their teacher in a regular classroom setting (Sullivan et al. 2015). Furthermore, teachers seem to use more symbolic gestures to support the verbal interaction with multilingual children (Gillanders 2007; Park 2014; Rosborough 2014; Vine 2006). Teachers might do so because they assume that nonverbal communication eases the understanding of the interaction. This way, children can participate in the classroom activities without fully understanding the vocabulary used. In addition, several studies found that teachers use simplified, low-complexity language when interacting with multilingual children (Lara-Alecio et al. 2009; Leung 1993; Ping 2014). However, as these studies often fail to make an active comparison between monolingual and multilingual children, it remains unclear how the teacher-child interactions of multilingual and monolingual children are shaped differently within the same classroom. Additionally, high behavioral engagement can be assumed to be beneficial for both monolingual and multilingual children. However, to date research on the differences in engagement between young children with diverse language backgrounds received little attention. As multilingual children are often growing up in two or more different cultures, they might have trouble following the norms and expectations on child socialization and development of the majority culture (Bossong and Keller, 2018; Greenfield et al. 2000). One study by Sullivan et al. (2015) found that multilingual children acted more often as a nonparticipating observer in activities than monolingual children, but found no significant difference in the engagement of monolingual and multilingual children.

\section{Taking a person-oriented approach in educational research}

Contrary to the common practice in the field of educational sciences, we adopt a personoriented approach, rather than a variable-oriented approach. A variable-oriented approach focuses on relations between variables or concepts, whereas a person-oriented approach allows for summarizing patterns within individuals (e.g., profiles), which offers a more comprehensive analysis of the diverse domains that play a role in the learning opportunities of individual children (Bergman and Trost 2006; Hickendorff et al. 2018). The person- 
oriented approach acknowledges the heterogeneity in young children and identifies homogenous subgroups that show similar developmental patterns (Hickendorff et al. 2018).

\section{Present study}

Previous research has shown that the quality of teacher-child interactions as well as a child's behavioral engagement during educational activities are important aspects of the learning opportunities of young children. However, multilingual children might be exposed to less beneficial learning opportunities because of differences in developmental trajectories and teacher bias. The present exploratory study builds on these findings by examining the unique contribution of each of the aspects of learning opportunities within individual children in relation to their monolingual or multilingual background. Thus, this study has three aims: (1) to identify subgroups of children according to (a) their individual teacher-child interactions and (b) their behavioral engagement in different classroom settings; (2) to examine whether multilingualism predicts membership for both the individual teacher-child interaction and the engagement profiles; and (3) to examine how teacher-child interaction and engagement profiles are related to each other. We will identify separate profiles of teacher-child interactions and behavioral engagement. By identifying profiles, we acknowledge the diversity and complexity of the interactions that children have with their teacher, as well as the role of classroom settings for the engagement of individual children, while providing a comprehensive overview of the learning opportunities that monolingual and multilingual children are exposed to.

\section{Method}

\section{Sample}

Below, we will describe the context in which this study was conducted, followed by the sampling method and attrition related to the longitudinal nature of this study. Finally, we will describe the background characteristics of the participants.

\section{Context of the study}

The present study was conducted in the Netherlands. In Dutch education, kindergarten entails the first two years of primary school (4-6 years old). The primary language of instruction is Dutch (apart from schools in the province of Friesland, where Frisian is also an official language of schooling). The schools in the present study were all located in neighborhoods with a prevalence of immigrants (i.e., at least one parent was born abroad) above national average (CBS 2013) and were therefore expected to serve ample multilingual children.

\section{Sampling and attrition}

The participants (5-6 years old) came from 20 kindergarten classrooms from 12 schools across the Netherlands. All kindergarten classrooms in participating schools with enough monolingual and multilingual children were included in the study. In each classroom, four children 
were selected (two multilingual, two monolingual; 80 children in total), henceforth referred to as the "focal children". In order to select focal children, teachers were asked to report which children in their classroom were multilingual, defined as children who habitually interacted in a language other than Dutch in their home environment. Monolingual children were children that spoke only Dutch, both at home and at school. When there were more than two multilingual children in one classroom, multilingual children were selected in such a way as to retain an even distribution in gender and socioeconomic status (SES; based on the Dutch school funding policy) within the classroom and across the sample. Monolingual focal children were matched to the multilingual children based on SES and gender. When there were multiple possibilities, children were selected randomly. All children present during the filming in the classroom had active parental consent for filming. Focal children were selected from the children for whom parental consent was also given for individual observation and assessment ( $93 \%$ of all parents).

Although we aimed for 40 children in both language groups, the final sample consisted of 76 children, of whom 43 were multilingual. This was due to three reasons. First, when comparing the available parent questionnaires (only 42 of $80(53 \%)$ parent questionnaires were returned) and the information provided by the teachers, four focal children that were monolingual according to the teacher, and selected as such by us, turned out to have frequent interactions in other languages than Dutch at home according to the parents. We decided to include them in the multilingual sample. Second, in one classroom, only one of the three monolingual children had parental consent for individual observations. Therefore, we included three multilingual children in that particular classroom. Third, one classroom dropped out of the project after the first observations because of teacher burnout. Furthermore, one multilingual child was ill during the observations of the first time point and will therefore only be included in the analyses of engagement.

\section{Background characteristics of the participants}

Background information on the teacher, classroom composition, and focal children is presented in Table 1. All teachers were native-Dutch speakers. Multilingual children spoke a wide variety of languages. Eight children interacted in two foreign languages at home; the home language was unknown for one child, although the teacher indicated that the child was multilingual. There were no statistically significant differences in gender, age, and SES between the language groups. The sample was representative of the Dutch population (CBS 2019). There is no official data on the languages spoken in the Netherlands. However, the languages of the biggest migrant groups in the Netherlands (i.e., Turkey-e.g., Turkish, Kurdish, Arabic; Morocco-e.g., Arabic, Moroccan, Berber; Indonesia-e.g., Indonesian) were all represented in our sample (CBS 2018).

\section{Design and procedure}

This study is part of a larger study with a longitudinal design of three time points in one school year; each roughly three months apart (October 2016, January 2017, April 2017). At each time point the same data was gathered. For this study, we used the teacher-child interaction data of time point 1, and the engagement data of all three time points (reasons explained under "Engagement"). Given the complex nature of this research project, we encourage researchers to contact the authors for further details on the followed procedures. 


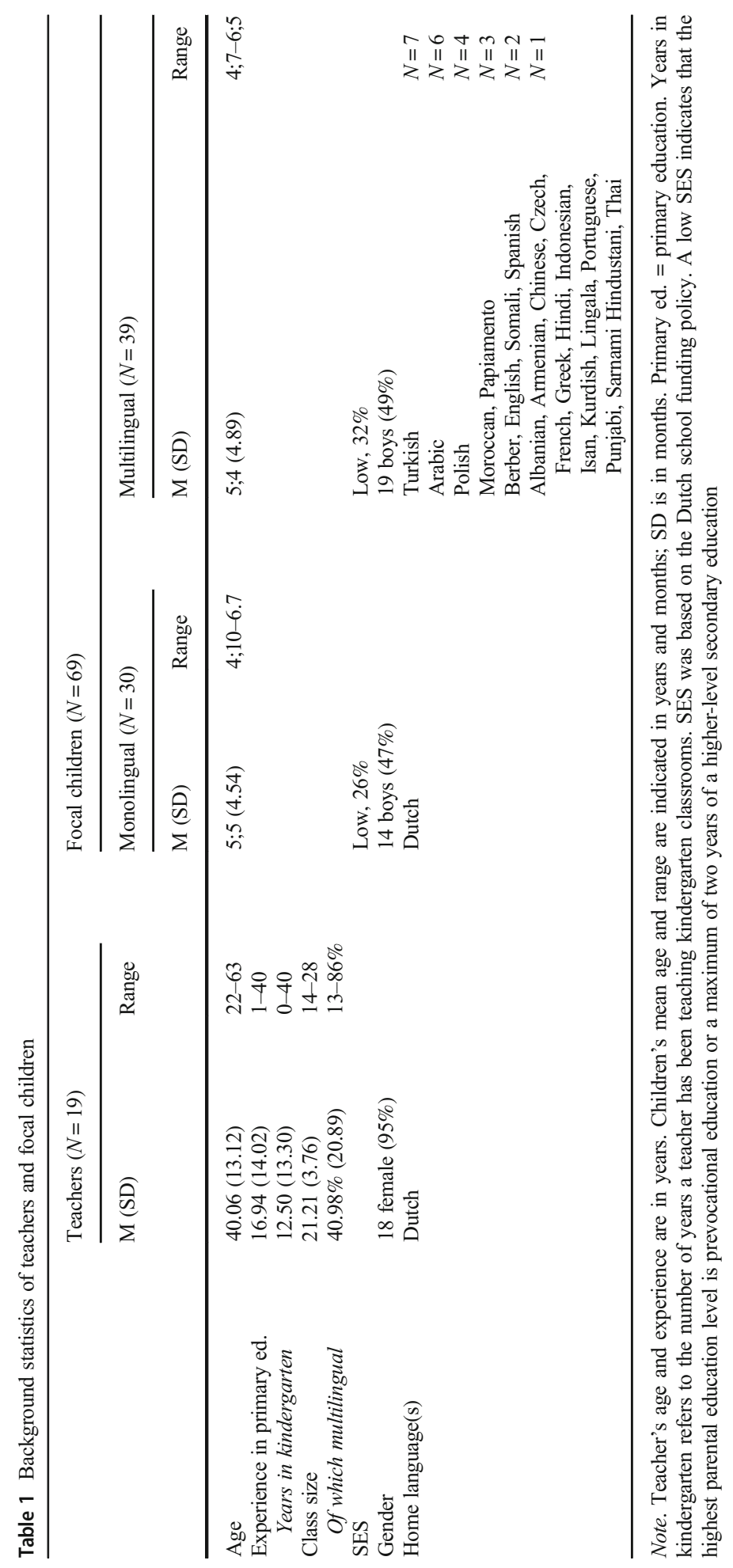


Two researchers came into the classroom for one morning to collect the data at each time point. One researcher filmed the teacher for the entire morning - excluding outdoor playincluding all interactions between the teacher and the focal children. Simultaneously, the other researcher observed the focal children to assess their engagement in diverse classroom settings. The filming and observations were conducted by the first author and twelve research-assistants. The research assistants were all final year Bachelor's students or Master's students in educational sciences or a related field. They were trained in two sessions on the observation of child engagement by the first author. In between the training sessions, training videos were independently coded. During the next session, all disagreements were discussed. The training took about eight hours in total. Before the second and third time point all research-assistants refreshed the observation rules with four training videos.

The videos were used for observing the individual teacher-child interactions. All interactions in which the teacher specifically addressed the focal child were considered individual teacher-child interactions. The interactions could take place with more children around (e.g., in circle time or in a small group), but in the analyses only the teacher utterances that specifically addressed the focal children were included. Three research-assistants, all Master's students in educational sciences or a related field, and the first author transcribed these segments of individual teacher-child interactions. The research-assistants were trained in transcription rules and conventions by the first author in three training sessions, of about ten hours in total. In between sessions, they independently transcribed video segments. Disagreements were discussed during the next session.

The transcripts were coded by another research-assistant and the first author. To limit the complexity of the coding procedure, the first author identified the codable utterances for each focal child (i.e., all utterances that were directed to a focal child or from the focal child him- or herself). The research-assistant only coded these utterances. She was a Master's student in educational sciences, trained in the coding scheme in five sessions by the first author. After each session new data was coded independently by both coders. Disagreements were discussed in the next session. After the coding of all transcripts, an internal audit by the authors revealed certain inconsistencies in the coding of language complexity that compromised the validity of it, although the construct was coded reliably. The first three authors discussed the issue and revised the definition and coding rules for language complexity. Consequently, the first author recoded all data for language complexity. The reliability of this coding was ensured with an audit. The first author randomly selected and coded ten segments from eight different transcripts (152 utterances), and discussed the codes with the second and third author. After the coding of all transcripts, the first author discussed all utterances $(N=25)$ that were difficult to make a decision about the corresponding coding with the second and third author, and they jointly agreed upon a code for each of these cases.

\section{Measures and variables}

\section{Demographic background information}

Before the start of the observations, the teachers completed a short questionnaire on their own professional background (i.e., age, gender, teaching experience, and professional training) and classroom composition (i.e., date of birth, gender, SES, and language background). The classroom composition information about the children was used to select the focal children. 
The parents also completed a questionnaire on the home literacy environment. This questionnaire included questions on the use of different languages with family and friends and in specific activities in the home environment (e.g., watching television, book reading, and playing).

\section{Individual teacher-child interactions}

To code individual teacher-child interactions, we developed a coding scheme (informed by Mascareño et al. 2016) that focused on the aspects of teacher-child interactions where potential differences could be expected between monolingual and multilingual children. The transcripts were coded on utterance level, and both teacher and child utterances were coded. Each utterance was coded on three dimensions: Communication channel, Type of utterance, and Language complexity. An overview of the coding scheme can be found in the Supplemental material.

The dimension Communication channel distinguishes between the use of verbal and nonverbal communication. Verbal utterances were further divided into verbal with and without meaningful gestures. Meaningful gestures included all gestures that were used to support the understanding of the meaning conveyed by a verbal utterance. The dimension Type of utterance was divided into six main categories: prompting, informing, response, follow-up, supporting flow, and residual. Utterances coded as supporting flow and residual were not used in the final analyses. The categories prompting, response, and follow-up are in combination also known as the initiation-response-feedback sequence (Sinclair \& Coulthard, 1975), but, in contrast to the traditional use, both teacher and child could initiate. Teacher initiations are most common during teacher-led activities, but as we included all interactions that happen during a day, children had more opportunity to initiate interactions as well. The dimension Language complexity was coded for teacher prompts (including open questions, closed questions, and directives) and child responses. These specific utterances were chosen, since these types of utterances could take different forms that reflect diverse levels of complexity. Utterances regarding behavioral control (i.e., redirecting child behavior) were not included in the coding of complexity, since this was not the focus of our research and complexity in these types of interaction might take a different form. In line with previous research, language complexity was coded using the literal-inferential distinction (Mascareño et al. 2016; Massey et al. 2008; Tompkins et al. 2013; van Kleeck et al. 2010).

The first author and a research assistant double coded nine segments from five different transcripts (157 utterances in total) to determine inter-rater agreement. On both dimensions, high agreement was found (channel: Krippendorff's $\alpha=0.98 ; 95 \%$ CI $[0.92 ; 1.00]$; type: Krippendorff's $\alpha=0.93 ; 95 \%$ CI $[0.88 ; 0.96])$. Reliability of language complexity was ensured using an audit procedure, as was described under "Design and procedure."

\section{Engagement}

Child behavioral engagement was assessed during real-time observations using the Situational Behavioral Engagement scale, an instrument specifically developed for this study. The focal children were observed for time intervals of five minutes using a visual analogue scale (Aitken 1969). Observers indicated on a ten-centimeter line how engaged the child was. This was transformed to a score between 0 (not engaged) and 100 (fully engaged). Three indicators were used to determine the engagement level: attention, dedication, and self-reliance (Laevers 
1993). An engaged child shows uninterrupted attention for the activity at hand, is dedicated with full focus on the task, and takes responsibility and initiative and is not fully dependent on the teacher. Although the indicators are separately described, they are not independent: A child that shows self-reliance needs dedication and attention for the activity at hand. Therefore, one general engagement score was given instead of separate scores for each indicator. Since we were interested in the engagement levels of children in different classroom settings, an engagement score was given every time, within the five-minute interval, the classroom setting of the observed focal child changed. Children could be observed in eight settings, based on the size of the group and the presence of the teacher: individual, individual with teacher, pair, pair with teacher, small group (3-6 children), small group with teacher, large group (more than 7 children), and large group with teacher.

Initially, analyses were planned on data from the first time point only. However, this resulted in too much missing data. As the observations only took place during one morning, individual children were not observed in all eight different settings. To overcome this, engagement data from the second and third time points was added. Twelve research assistants and the first author conducted the observations. They coded five training videos for reliability assessment. This showed good reliability for both engagement (ICC $=0.84 ; 95 \%$ CI $[-0.07$; $1.00]$ ) and setting (Krippendorff's $\alpha=0.74 ; 95 \%$ CI [0.64;0.82]).

\section{Analyses}

In the process of analyzing the data, we took several steps. First, we prepared the interaction and observation data for profile analysis. Second, we identified the profiles for interaction and engagement. Third, we analyzed the predictive value of multilingualism. Finally, we examined the relations in profile membership of the interaction and engagement profiles. All steps are described in more detail below.

\section{Data pre-processing for profile extraction}

To identify the profiles for teacher-child interactions and behavioral engagement, raw data had to be pre-processed to create interpretable predictors for the profiles. We were interested in three aspects of the interaction: quantity of the interaction, complexity of the interaction, and communication channel. We included the quantity of interaction by taking the total amount of relevant utterances for each child. For complexity, we focused on the complexity of teacher prompts, child responses, and the use of elaborative followups by the teacher (i.e., elaborations and hints). Furthermore, for communication channel, we made a comparison between the use of meaningful gestures (i.e., completely nonverbal utterances and verbal utterances supported by symbolic gestures) and completely verbal utterances. This included all child utterances and all teacher utterances that were specifically directed to the child. As there were large differences across children between the number of utterances that children produced and were exposed to, the raw frequencies for all predictors were adjusted to correct for this difference. We assumed that being exposed to and producing more utterances in general would also increase the probability of showing higher frequencies of the different predictors. We therefore calculated a unique weight for each child and used that to adjust the raw frequencies. These adjustments made the frequencies equivalent across classrooms, and could therefore be compared to interactions of average length. Weighted frequencies 
were used in the subsequent analyses. The quantity of interaction was corrected for the total length of the video for that particular classroom.

For the profiles of behavioral engagement, we were interested in the role of group size and presence of the teacher on the engagement levels of children. The eight classroom settings that were observed were merged to three main settings: small group with teacher (including small group, pair and individual with teacher), small group without teacher (including small group, pair and individual without teacher), and large group (including large group with and without teacher). We calculated an engagement score for each child in each setting by averaging all scores in the included settings. Since multiple observations could take place in the five-minute interval, we corrected for the length of observation.

\section{Profiles of teacher-child interactions and engagement}

We identified separate profiles for the child's engagement and the individual teacher-child interactions using Latent Profile Analysis (LPA) in MPlus Version 8 (Muthén \& Muthén 1998-2017). Child engagement profiles were estimated considering their individual engagement scores across the three categories of classroom settings (small group without teacher, small group with teacher, large group). Profiles of individual teacher-child interactions were based on the weighted frequencies of teacher and child meaningful gestures, teacher complex prompts, child complex responses, teacher elaborate followups, and quantity of interaction. Model fit of the LPA was determined based on the (1) Bayesian information criterion (BIC), (2) Akaike information criterion (AIC), (3) entropy, (4) Lo-Mendell-Rubin adjusted likelihood ratio test, and (5) interpretability of the profiles. A lower BIC and AIC indicate better fit. A high entropy score (above 0.80) indicates better fit. A significant likelihood ratio test indicates a better fit than the model with one less profile. To take into account the nested structure of the data, a sandwich estimator was used $($ TYPE $=$ COMPLEX).

\section{Predictive value of multilingualism on profiles of teacher-child interactions and engagement}

We tested whether there was an association between multilingualism and the probabilities of membership to different teacher-child interaction and engagement profiles. Therefore, a multinomial logistic regression was conducted in MPlus Version 8 with profile membership as the dependent variable and multilingualism as the independent variable. The alpha level was set at 0.05 . Profile membership was determined by modal assignment (i.e., all children were assigned to their profile with the highest posterior probability). Again, a sandwich estimator (TYPE $=$ COMPLEX) was used to account for the nested structure in the data.

\section{Relation between interaction and engagement profiles}

To explore the relation between engagement and teacher-child interaction profile membership, we created a crosstab with both profiles for monolingual and multilingual children. We conducted a descriptive analysis of the co-occurrence of specific interaction and engagement profiles. Because of the small sample size we could not statistically test these relations. 


\section{Results}

This section will describe the results of the conducted analyses. We first describe the individual teacher-child interactions and child engagement, followed by short descriptions of all identified profiles (incl. proportions for profile membership). Subsequently, we describe the relations between multilingualism and profile membership. Finally, the relations between the profiles of interactions and engagement are described.

\section{Descriptive results}

Detailed descriptive statistics are presented in Table 2 for interactions and in Table 3 for engagement. The results show a wide variety in the quantity of interaction, ranging from only 17.54 utterances to 366.50 utterances per child in the course of a day. On average, both teachers and children used mainly utterances of low complexity (teacher prompts, $13.77 \%$ complex prompts; child responses, $24.15 \%$ complex responses; teacher followups, $17.64 \%$ elaborate follow-ups). Children used relatively more meaningful gestures, either in completely nonverbal utterances or to support a verbal utterance $(46.13 \%)$ than teachers $(14.40 \%)$.

The three categories of classroom settings (small group without teacher, small group with teacher, and large group) were used as predictors for the engagement profiles. On average, across the three time points, focal children were 5.70 times observed in small group settings without the teacher $(S D=11.27$; range, 1-12), 2.33 times in small group settings with the teacher $(S D=1.75$; range, $0-7)$, and 11.14 times in large group settings $(S D=4.14$; range, 1-20). Results of the full sample revealed that children in general showed moderate engagement in all settings. There was a wide range in engagement levels between children in all settings.

\section{Profiles of individual teacher-child interactions}

LPA for the individual teacher-child interactions was conducted for two-, three-, four-, and five-profile solutions. Both the three- and five-profile solutions showed good fit (Table 4). Since the interpretation of the five-profile solution was more informative than the interpretation of the three-profile solution, we proceeded with the five-profile solution. Figure 1 shows a graphical representation of these profiles. The means, standard deviations, and ranges are presented in Table 2. Henceforth, we have characterized and labeled the profiles, including their prevalence in the focal children. We also gave each profile a short tag name, to be used in tables and figures. These tags reflect the four components in the profiles-i.e., gestures $(\mathrm{G})$, complexity $(\mathrm{C})$, elaborate follow-ups (FU), and quantity (Q) - and the level of each of the components-i.e., above average (+), close to average $( \pm)$, and below average $(-)$.

- Profile 1: low quantity of typical interactions $\left(\mathrm{G} \pm \mathrm{C} \pm \mathrm{FU} \pm \mathrm{Q}^{-}\right)$. This was the profile with the highest prevalence, including half of all focal children $(51.0 \%)$. The interactions of the children in this profile can be characterized as typical interactions, comparable to the sample mean. Their interactions had a mix of verbal and nonverbal utterances, and high and low complex utterances. However, they had a low quantity of interaction with their teacher. 


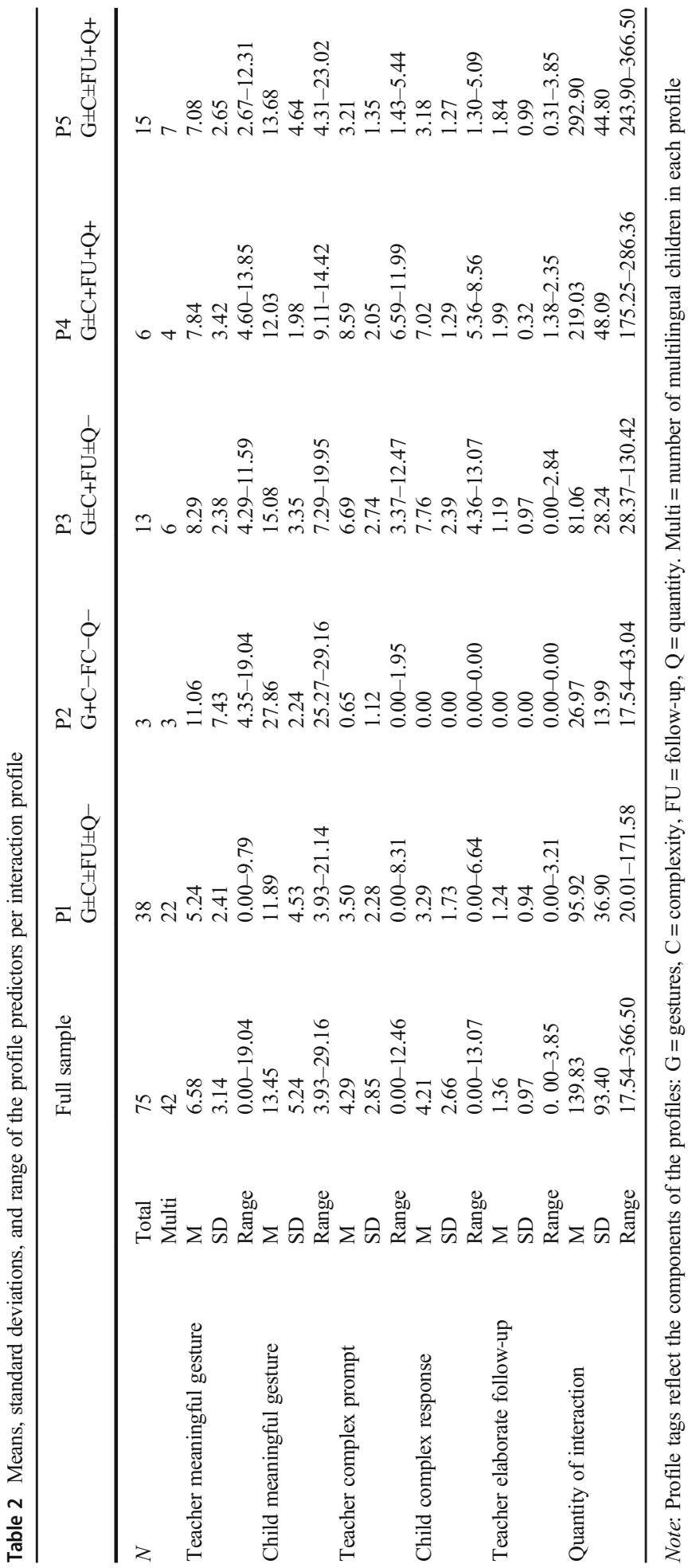


Table 3 Means, standard deviations, and ranges of the profile predictors per engagement profile

\begin{tabular}{|c|c|c|c|c|c|c|c|}
\hline & & Full sample & $\begin{array}{l}\text { P1 } \\
\text { S-ST-L- }\end{array}$ & $\begin{array}{l}\mathrm{P} 2 \\
\mathrm{~S}-\mathrm{ST}-\mathrm{L}+\end{array}$ & $\begin{array}{l}\mathrm{P} 3 \\
\mathrm{~S}+\mathrm{ST}+\mathrm{L} \pm\end{array}$ & $\begin{array}{l}\mathrm{P} 4 \\
\mathrm{~S}+\mathrm{ST} \pm \mathrm{L}-\end{array}$ & $\begin{array}{l}\mathrm{P} 5 \\
\mathrm{~S}+\mathrm{ST}+\mathrm{L}+\end{array}$ \\
\hline \multirow[t]{2}{*}{$N$} & Total & 76 & 13 & 6 & 31 & 4 & 22 \\
\hline & Multi & 43 & 9 & 5 & 14 & 4 & 11 \\
\hline \multirow[t]{2}{*}{ Small group } & M & 66.00 & 57.56 & 47.94 & 69.76 & 77.70 & 68.48 \\
\hline & SD & 11.90 & 10.24 & 6.88 & 10.50 & 10.24 & 8.46 \\
\hline \multirow{3}{*}{$\begin{array}{l}\text { Small group }+ \\
\text { teacher }\end{array}$} & $\mathrm{M}$ & 71.09 & 49.38 & 55.31 & 77.56 & 69.63 & 77.85 \\
\hline & $\mathrm{SD}$ & 14.28 & 8.77 & 10.06 & 9.01 & 10.08 & 9.05 \\
\hline & Range & $36.01-96.00$ & $36.01-64.16$ & $38.00-64.50$ & $63.00-96.00$ & $58.00-76.00$ & $63.71-95.00$ \\
\hline \multirow[t]{3}{*}{ Large group } & $\mathrm{M}$ & 64.73 & 55.72 & 70.59 & 61.47 & 39.72 & 77.59 \\
\hline & $\mathrm{SD}$ & 10.90 & 5.28 & 3.82 & 4.22 & 1.28 & 3.37 \\
\hline & Range & $38.61-83.28$ & $47.36-62.49$ & $67.46-77.27$ & $50.84-68.52$ & $38.61-41.50$ & $72.42-83.28$ \\
\hline
\end{tabular}

Note: Profile tags reflect the classroom settings of the profiles: $\mathrm{S}=$ small group without teacher, $\mathrm{ST}=$ small group with teacher, $\mathrm{L}=$ large group. Multi = number of multilingual children in each profile

- Profile 2: low quantity of nonverbal, non-complex interactions ( $\left.\mathrm{G}+\mathrm{C}-\mathrm{FU}-\mathrm{Q}^{-}\right)$. This profile had only three children $(4.0 \%)$ and was characterized by the almost complete absence of complex utterances. These children had the lowest amount of interactions. Furthermore, their interactions often were of a nonverbal nature, using many meaningful gestures.

- Profile 3: low quantity of high complex interactions $\left(\mathrm{G} \pm \mathrm{C}+\mathrm{FU}+\mathrm{Q}^{-}\right)$. Children in this profile $(18.1 \%)$ used both nonverbal and verbal communication in their interactions, comparable to the sample mean. Their interactions were of high complexity in both the teacher prompts, as well as in the child responses. The teacher used an average amount of elaborative follow-ups. The quantity of interaction was low.

- Profile 4: high quantity of high complex interactions $(\mathrm{G} \pm \mathrm{C}+\mathrm{FU}+\mathrm{Q}+)$. This profile is similar to profile 3 . Interactions with these children (7.1\%) include both nonverbal and verbal communication, comparable to the sample mean, and both teachers and children used many complex utterances in their prompts and responses. As opposed to the interactions of the children in profile 3 , the teacher used many elaborative follow-ups in interaction with children in profile 4 . Furthermore, the children had many interactions with their teacher, whereas the children in profile 3 had only limited interactions.

- Profile 5: high quantity of followed-up interactions $(\mathrm{G} \pm \mathrm{C} \pm \mathrm{FU}+\mathrm{Q}+)$. Children in this profile $(19.9 \%)$ had the most interactions with their teachers; these were of average complexity in both teacher prompts and child responses, but with a high use of elaborative follow-ups. Both children and teachers used a combination of verbal utterances and meaningful gestures comparable to the sample mean.

Table 4 Model fit latent profile analysis for interactions

\begin{tabular}{llllll}
\hline \# of profiles & AIC & BIC & Entropy & LMR LRT $(p)$ & adjusted \\
\hline 2 & 2660.505 & 2704.538 & 0.976 & (vs 1 class) & 0.2185 \\
3 & 2632.390 & 2692.644 & 0.987 & (vs 2 classes) & 0.3736 \\
4 & 2623.209 & 2699.686 & 0.873 & (vs 3 classes) & 0.7724 \\
5 & 2615.914 & 2708.614 & 0.913 & (vs 4 classes) & 0.3848 \\
\hline
\end{tabular}




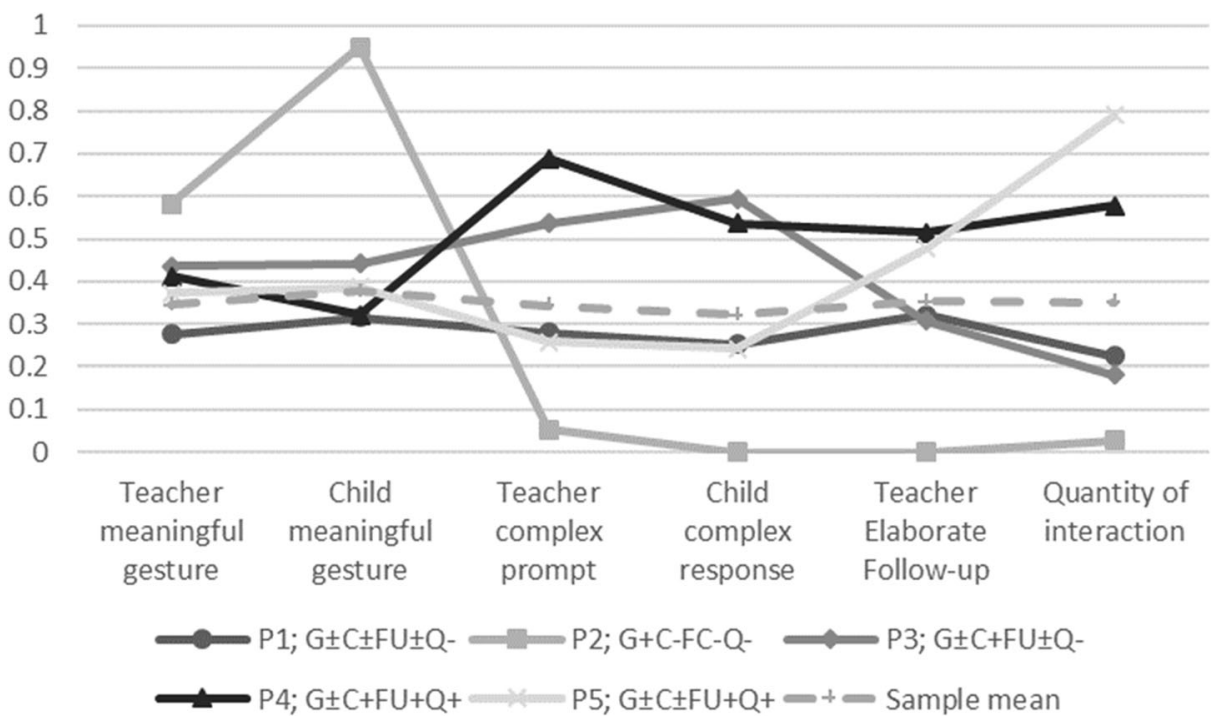

Fig. 1 Channel, complexity, and quantity of interaction for all interaction profiles. Note: Profile tags reflect the components of the profiles: $\mathrm{G}=$ gestures, $\mathrm{C}=$ complexity, $\mathrm{FU}=$ follow-up, $\mathrm{Q}=$ quantity

\section{Profiles of child engagement}

LPA was conducted to identify the profiles for engagement for a solution with two, three, four, and five profiles. The model fit for all solutions is presented in Table 5. Model fit indicators showed that the five-profile solution had the best fit to the data. Figure 2 shows a graphical representation of the engagement levels across the three different settings for each profile. Table 3 shows the means, standard deviations, and ranges of the engagement scores in each setting for each profile and for the complete sample. Henceforth, these five profiles have been characterized and labeled, including the percentage of focal children in each profile. Tag names were given to reflect the characteristics of the profiles in tables and figures. These tags include the setting - small group without teacher (S), small group with teacher (ST), and large groupand the level of engagement - above average $(+)$, close to average $( \pm)$, and below average $(-)$.

- Profile 1: low engagement (S-ST-L-). Children in this profile (17.10\%) were among the lowest-scoring focal children on engagement across all settings. Their engagement levels were below average in all settings. In the "small group with the teacher" setting, these children had the lowest engagement score compared to the other profiles.

Table 5 Model fit latent profile analysis for engagement

\begin{tabular}{llllll}
\hline \# of profiles & AIC & BIC & Entropy & LMR LRT $(p)$ & adjusted \\
\hline 2 & 1714.983 & 1738.290 & 0.752 & (vs 1 class) & 0.159 \\
3 & 1714.955 & 1747.586 & 0.804 & (vs 2 classes) & 0.566 \\
4 & 1716.582 & 1758.535 & 0.807 & (vs 3 classes) & 0.786 \\
5 & 1707.585 & 1758.862 & 0.900 & (vs 4 classes) & 0.088 \\
\hline
\end{tabular}


- Profile 2: low small-group engagement $(\mathrm{S}-\mathrm{ST}-\mathrm{L}+)$. The six children in this profile (7.90\%) showed low engagement in both small-group settings, although particularly low levels in the "small group without the teacher" setting. In contrast to their engagement levels in small-group settings, these children showed high engagement in large-group settings.

- Profile 3: high-moderate engagement $(\mathrm{S}+\mathrm{ST}+\mathrm{L} \pm)$. This was the profile with the highest prevalence, including 31 of the 76 children $(40.80 \%)$. Children in this profile showed high engagement levels in both small group settings and moderate engagement levels in large group settings.

- Profile 4: high small-group and low large-group engagement ( $\mathrm{S}+\mathrm{ST} \pm \mathrm{L}-$ ). This profile only included four children $(5.26 \%)$. These children had high engagement levels in small-group settings without the teacher, close to average levels in small-group settings with the teacher, and the lowest engagement levels in large-group settings.

- Profile 5: high engagement $(\mathrm{S}+\mathrm{ST}+\mathrm{L}+)$. Children in this profile $(28.95 \%)$ showed very similar, high engagement levels in small-group settings as those in profile 3 . However, as opposed to the children in profile 3 , children in profile 5 also showed high engagement in the large-group setting.

\section{Predictive value of multilingualism on teacher-child interaction}

The distribution of multilingual children over the interaction profiles is presented in Table 2. In all but one profile, the distribution is fairly even between monolingual and multilingual children. In profile 2 (i.e., low quantity of nonverbal, low complex interactions), all children $(N=3)$ were multilingual. The predictive value of multilingualism on profile membership was assessed using multinomial logistic regression. The results are presented in Table 6 . Since profile 2 had only three children, the odds ratio became extreme and cannot be interpreted. No significant differences

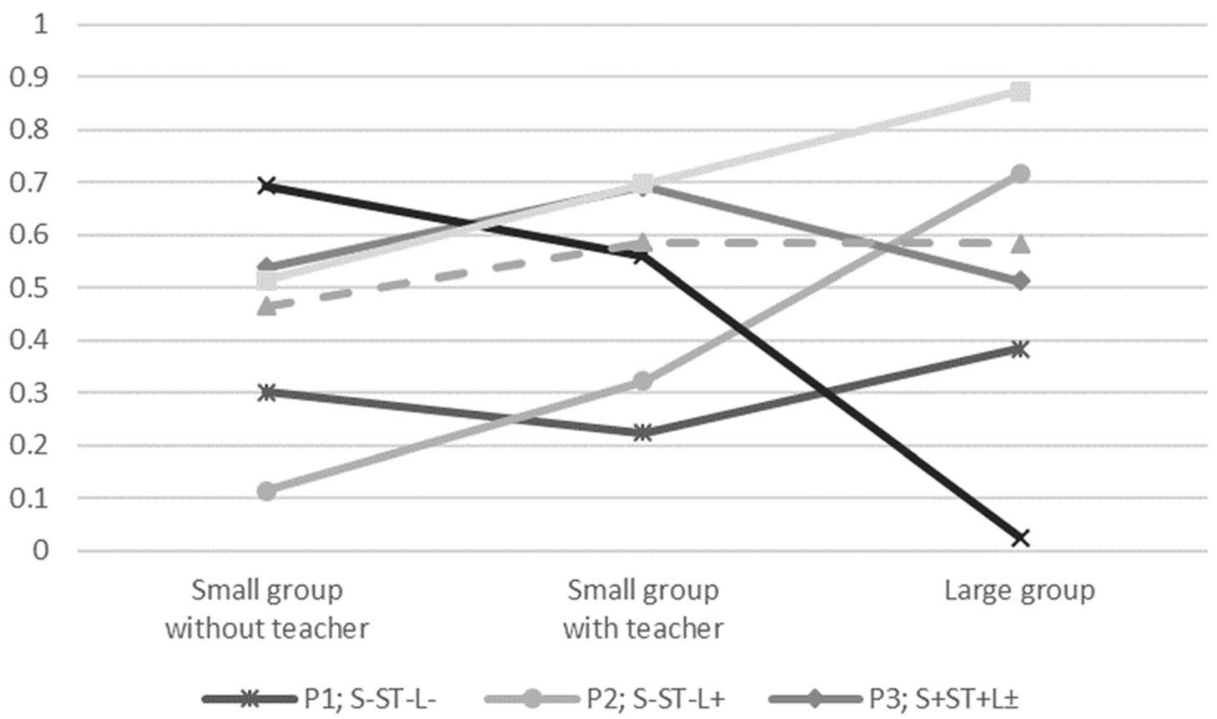

Fig. 2 Engagement scores across settings for each profile. Note: Profile tags reflect the classroom settings of the profiles: $\mathrm{S}=$ small group, $\mathrm{ST}=$ small group with teacher, $\mathrm{L}=$ large group 
Table 6 Odds ratio and confidence intervals of multinomial logistic regression with interaction profiles

\begin{tabular}{|c|c|c|c|c|c|}
\hline & & \multicolumn{4}{|c|}{ Reference group } \\
\hline & & $\begin{array}{l}\mathrm{P} 2 \\
\mathrm{G}+\mathrm{C}- \\
\mathrm{FU}-\mathrm{Q}-\end{array}$ & $\begin{array}{l}\mathrm{P} 3 \\
\mathrm{G} \pm \mathrm{C}+ \\
\mathrm{FU} \pm \mathrm{Q}^{-}\end{array}$ & $\begin{array}{l}\mathrm{P} 4 \\
\mathrm{G} \pm \mathrm{C}+ \\
\mathrm{FU}+\mathrm{Q}+\end{array}$ & $\begin{array}{l}\mathrm{P} 5 \\
\mathrm{G} \pm \mathrm{C} \pm \\
\mathrm{FU}+\mathrm{Q}+\end{array}$ \\
\hline $\mathrm{P} 1$ & Odds ratio & Extreme & 1.60 & 0.69 & 1.57 \\
\hline $\mathrm{G} \pm \mathrm{C} \pm \mathrm{FU} \pm \mathrm{Q}^{-}$ & $\begin{array}{l}95 \% \mathrm{CI} \\
p\end{array}$ & $<0.001$ & $\begin{array}{l}-0.61 ; 1.55 \\
0.391\end{array}$ & $\begin{array}{l}-1.97 ; 1.22 \\
0.646\end{array}$ & $\begin{array}{l}-0.42 ; 1.32 \\
0.307\end{array}$ \\
\hline $\begin{array}{l}\mathrm{P} 2 \\
\mathrm{G}+\mathrm{C}-\mathrm{FC}-\mathrm{Q}-\end{array}$ & $\begin{array}{l}\text { Odds ratio } \\
95 \% \text { CI }\end{array}$ & & Extreme & Extreme & Extreme \\
\hline & $p$ & & $<0.001$ & $<0.001$ & $<0.001$ \\
\hline P3 & Odds ratio & & & 0.43 & 0.98 \\
\hline $\mathrm{G} \pm \mathrm{C}+\mathrm{FU} \pm \mathrm{Q}^{-}$ & $\begin{array}{l}95 \% \mathrm{CI} \\
p\end{array}$ & & & $\begin{array}{l}0.07 ; 2.68 \\
0.365\end{array}$ & $\begin{array}{l}0.25 ; 3.81 \\
0.976\end{array}$ \\
\hline P4 & Odds ratio & & & & 2.29 \\
\hline $\mathrm{G} \pm \mathrm{C}+\mathrm{FU}+\mathrm{Q}+$ & $\begin{array}{l}95 \% \mathrm{CI} \\
p\end{array}$ & & & & $\begin{array}{l}0.32 ; 16.36 \\
0.410\end{array}$ \\
\hline
\end{tabular}

Note: Profile tags reflect the components of the profiles: $\mathrm{G}=$ gestures, $\mathrm{C}=$ complexity, $\mathrm{FU}=$ follow-up, $\mathrm{Q}=$ quantity, $95 \% \mathrm{CI}=95 \%$ confidence interval

were found between the other profiles. Multilingualism does not predict profile membership for individual teacher-child interactions.

\section{Predictive value of multilingualism on engagement}

Next, the predictive value of multilingualism on membership of engagement profiles was assessed. Table 3 shows the number of multilingual children in each profile for engagement. In the two profiles with the highest prevalence, profiles 3 (i.e., highmoderate engagement) and 5 (i.e., high engagement), about half of the children is multilingual. In the other three profiles, the majority of the children is multilingual. Profile 4 (i.e., high small group and low large group engagement) includes only multilingual children, and in profile 2 (i.e., low small group engagement), only one of the six children is monolingual. To assess the predictive value of multilingualism on the engagement profiles, a multinomial logistic regression was conducted. The results are presented in Table 7. Again, as profile 4 has only four children that are all multilingual, odds ratios become extremely large and cannot be interpreted.

The relative probability of being in profile 2 (i.e., low small group engagement) rather than profile 3 (i.e., high-moderate engagement) was significantly higher $(\mathrm{OR}=6.07)$ for multilingual children than the corresponding probability for monolingual children. The same trend was visible for the relative probability of being in profile 2 rather than profile 1 (i.e., low engagement) or 5 (high engagement); however, it was less strong and not significant. Again, profile 2 is a rather small profile with only 6 children, 5 of whom are multilingual. So results should be handled with great caution.

\section{Relation between interaction and engagement profiles}

Finally, we combined the two profiles to determine how the interaction and engagement profiles were related to each other. The results are shown in Table 8. Since our sample size is 
Table 7 Odds ratio and confidence intervals of multinomial logistic regression with engagement profiles

\begin{tabular}{|c|c|c|c|c|c|}
\hline & & \multicolumn{4}{|c|}{ Reference group } \\
\hline & & $\begin{array}{l}\mathrm{P} 2 \\
\mathrm{~S}-\mathrm{ST}-\mathrm{L}+\end{array}$ & $\begin{array}{l}\mathrm{P} 3 \\
\mathrm{~S}+\mathrm{ST}+\mathrm{L} \pm\end{array}$ & $\begin{array}{l}\mathrm{P} 4 \\
\mathrm{~S}+\mathrm{ST} \pm \mathrm{L}-\end{array}$ & $\begin{array}{l}\text { P5 } \\
\text { S+L+ }\end{array}$ \\
\hline Pl & Odds ratio & 0.45 & 2.73 & Extreme & 2.25 \\
\hline $\mathrm{S}-\mathrm{ST}-\mathrm{L}-$ & $\begin{array}{l}95 \% \text { CI } \\
p\end{array}$ & $\begin{array}{l}0.07 ; 2.88 \\
0.399\end{array}$ & $\begin{array}{l}0.90 ; 8.34 \\
0.078\end{array}$ & $>0.001$ & $\begin{array}{l}0.57 ; 8.85 \\
0.246\end{array}$ \\
\hline $\mathrm{P} 2$ & Odds ratio & & 6.07 & Extreme & 5.00 \\
\hline $\mathrm{S}-\mathrm{ST}-\mathrm{L}+$ & $\begin{array}{l}95 \% \text { CI } \\
p\end{array}$ & & $\begin{array}{l}1.62 ; 22.66 \\
0.007\end{array}$ & $>0.001$ & $\begin{array}{l}0.97 ; 25.83 \\
0.055\end{array}$ \\
\hline P3 & Odds ratio & & & Extreme & 0.82 \\
\hline $\mathrm{S}+\mathrm{ST}+\mathrm{L} \pm$ & $\begin{array}{l}95 \% \mathrm{CI} \\
p\end{array}$ & & & $>0.001$ & $\begin{array}{l}0.28 ; 2.41 \\
0.723\end{array}$ \\
\hline $\begin{array}{l}\mathrm{P} 4 \\
\mathrm{~S}+\mathrm{ST} \pm \mathrm{L}-\end{array}$ & $\begin{array}{l}\text { Odds ratio } \\
95 \% \text { CI }\end{array}$ & & & & Extreme \\
\hline & $p$ & & & & $>0.001$ \\
\hline
\end{tabular}

Note: Profile tags reflect the classroom settings of the profiles: $\mathrm{S}=$ small group without teacher, $\mathrm{ST}=$ small group with teacher, $\mathrm{L}=$ large group, $95 \% \mathrm{CI}=95 \%$ confidence interval

rather small, the cross-tabulation is scattered, and therefore, it was not possible to conduct statistical testing of the associations.

All monolingual children that had a high quantity of interaction with their teacher (i.e., interaction profiles 4 and 5) showed moderate to high engagement across settings (i.e., engagement profiles 3 and 5). This co-occurrence does not appear for the multilingual children. Furthermore, monolingual and multilingual children that had high complex interactions (i.e., interaction profiles 3 and 4) are also primarily represented in the moderate to high engagement profiles (i.e., engagement profiles 3 and 5). From the three multilingual children

Table 8 Crosstab of interaction and engagement profiles with multilingual language background

\begin{tabular}{|c|c|c|c|c|c|c|c|c|}
\hline & & & \multicolumn{5}{|c|}{ Engagement } & \multirow[t]{2}{*}{ Total } \\
\hline & & & $\begin{array}{l}\text { PI } \\
\text { S-ST-L- }\end{array}$ & $\begin{array}{l}\mathrm{P} 2 \\
\mathrm{~S}-\mathrm{ST}-\mathrm{L}+\end{array}$ & $\begin{array}{l}\mathrm{P} 3 \\
\mathrm{~S}+\mathrm{ST}+\mathrm{L} \pm\end{array}$ & $\begin{array}{l}\mathrm{P} 4 \\
\mathrm{~S}+\mathrm{ST} \pm \mathrm{L}-\end{array}$ & $\begin{array}{l}\mathrm{P} 5 \\
\mathrm{~S}+\mathrm{ST}+\mathrm{L}+\end{array}$ & \\
\hline \multirow{11}{*}{$\begin{array}{l}\text { Teacher-child } \\
\text { interactions }\end{array}$} & $\mathrm{P} 1$ & Monolingual & 3 & 1 & 9 & 0 & 3 & \multirow[t]{2}{*}{38} \\
\hline & $\mathrm{G} \pm \mathrm{C} \pm \mathrm{FU} \pm \mathrm{Q}^{-}$ & Multilingual & 3 & 4 & 7 & 2 & 6 & \\
\hline & $\mathrm{P} 2$ & Monolingual & 0 & 0 & 0 & 0 & 0 & \multirow[t]{2}{*}{3} \\
\hline & $\mathrm{G}+\mathrm{C}-\mathrm{FC}-\mathrm{Q}-$ & Multilingual & 2 & 0 & 1 & 0 & 0 & \\
\hline & $\mathrm{P} 3$ & Monolingual & 1 & 0 & 3 & 0 & 3 & \multirow[t]{2}{*}{13} \\
\hline & $\mathrm{G} \pm \mathrm{C}+\mathrm{FU} \pm \mathrm{Q}^{-}$ & Multilingual & 1 & 1 & 4 & 0 & 0 & \\
\hline & $\mathrm{P} 4$ & Monolingual & 0 & 0 & 1 & 0 & 1 & \multirow[t]{2}{*}{6} \\
\hline & $\mathrm{G} \pm \mathrm{C}+\mathrm{FU}+\mathrm{Q}+$ & Multilingual & 0 & 0 & 0 & 0 & 4 & \\
\hline & P5 & Monolingual & 0 & 0 & 4 & 0 & 4 & \multirow[t]{3}{*}{15} \\
\hline & $\mathrm{G} \pm \mathrm{C} \pm \mathrm{FU}+\mathrm{Q}+$ & Multilingual & 3 & 0 & 1 & 2 & 1 & \\
\hline & Total & & 13 & 6 & $30^{\mathrm{a}}$ & 4 & 22 & \\
\hline
\end{tabular}

Note: Profile tags reflect the components of the interaction profiles: $\mathrm{G}=$ gestures, $\mathrm{C}=$ complexity, $\mathrm{FU}=$ followup, $\mathrm{Q}=$ quantity; and the settings of the engagement profiles: $\mathrm{S}=$ small group; $\mathrm{ST}=$ small group with teacher; $\mathrm{L}=$ large group

${ }^{a}$ One child is missing, as no interaction profile could be calculated for this child 
in interaction profile 2 (i.e., low quantity of nonverbal, low complex interactions), two were part of engagement profile 1 (i.e., low engagement). These children did not only have very limited interactions with their teacher, with much nonverbal communication and low complexity, they also showed low engagement across all classroom settings. The third child in interaction profile 2 showed moderate to high engagement across classroom settings (i.e., engagement profile 3).

\section{Discussion}

The general purpose of this study was to obtain a better understanding of the learning opportunities that monolingual and multilingual children are exposed to in interactions with their teacher. We took a person-oriented approach to explore the existence of distinct profiles of the characteristics of individual teacher-child interactions, and of behavioral engagement in diverse classroom settings. Consequently, profile membership was compared for monolingual and multilingual children. Lastly, the co-occurrence of the engagement and interaction profiles was explored.

We identified five profiles for teacher-child interactions that differed in the use of meaningful gestures, level of complexity, and the quantity of interaction. Four of the five profiles showed moderate use of gestures in the interaction, whereas one profile showed a high prevalence of nonverbal communication (i.e., interaction profile 2). All children in this profile were multilingual. Teachers often use more nonverbal communication, such as symbolic gestures, in interaction with multilingual children to support the understanding of verbal interaction (Gillanders 2007; Park 2014; Rosborough 2014; Vine 2006). Furthermore, profiles with a higher prevalence of elaborate teacher follow-ups also had a higher quantity of interaction. This suggests that, by using elaborate follow-ups, teachers gave the opportunity for extended discourse and, therefore, for longer interactions. Extended discourse assigns children a more active role in the interaction, and creates space for reasoning and discussion (Michaels and O'Connor, 2015). However, teachers do not often use elaborate follow-ups in interaction with young children (Dickinson et al. 2003; Mascareño et al. 2016). The present study adds to that by showing that the exposure to extended discourse does not only differ between classrooms, but also individual children within the same classroom get different opportunities for extended discourse.

We did not find any differences in the representation of monolingual versus multilingual children on the teacher-child interaction profiles. Previous research (de Oliveira, Gilmetdinova, \& Pelaez-Morales, 2016; Lara-Alecio et al. 2009; Ping 2014) suggests that teachers use simplification strategies in interaction with multilingual children, such as the use of more nonverbal communication and less complex utterances. Our study did not replicate those findings. This is a promising result as it suggests the possible absence of teacher bias in interactions with multilingual children, meaning the opportunities children get in interactions with their teacher are not related to them being monolingual or multilingual.

We, furthermore, identified five profiles of behavioral engagement. We found differences in engagement levels across profiles, and between classroom settings within profiles. Differences between engagement profiles were mainly determined by the size of the group involved in the activity, and not by the presence of the teacher. About one third of all children in our sample showed low engagement levels in one or more settings. Previous research has shown the importance of engaging in all sorts of settings, as children have different affordances. 
Large-group settings, such as circle time, are generally used to expose children to print materials, such as books, complex oral language, and early literacy (Cabell et al. 2013). Additionally, in small-group settings, children have more chances to participate in interactions with teachers and peers and are able to select their own activities.

Multilingual children seemed to show lower engagement levels across settings. These results suggest that teachers struggle to engage multilingual children in classroom activities - both in small- and large-group settings - that connect to their interests and knowledge. Regular classroom activities aimed at children from the majority language and culture might be less appealing to multilingual children, for whom there might be a weaker link to the background knowledge they acquired within their home context (Gregory, 1993; Razfar and Rumenapp 2012).

The third aim was to examine how engagement and interaction profiles co-occur. The results showed that children that had richer teacher-child interactions (i.e., high complexity and/or high quantity) also showed moderate to high engagement across classroom settings. This relation was more apparent for monolingual children than for multilingual children. This is in line with previous research (Cirino et al. 2007; Williford et al. 2013). Our findings suggest that children will be more engaged when they have interactions with their teacher that stimulate dialogue, provide elaborate follow-ups, and expand their vocabulary. Likewise, teachers might be more inclined to engage in extended discourse with students who show engaged behavior.

We recognize several limitations in our study. First, the sample size of the present study was rather small and results should therefore be interpreted with caution. Moreover, some of the profiles are small and could therefore not be interpreted for the logistic regression. The small sample size is a consequence of our focus on individual children, which allowed us to collect a rich data set that offered detailed information on the learning opportunities of monolingual and multilingual children. Second, the present study addressed the multilingual children as a homogenous group. There are, however, many characteristics that might partly explain the learning opportunities that they are involved in. This includes, for example, a child's language proficiency and exposure in all their languages, socioeconomic status, and home literacy environment (Cummins 1979). Simplifying multilingualism to a binary variable, as happens in most studies, could be considered a questionable decision, although understandable. To capture the nature of multilingualism, we collected information about the child's home language background using a parent questionnaire, including questions on which languages were used across settings and activities and with different people. Unfortunately, only about half of the questionnaires were returned, which forced us to operationalize multilingualism as a binary variable. The questionnaires we did receive, combined with the information provided by the teacher, showed that the multilingual children indeed varied widely in terms of home language(s), language exposure, and socioeconomic status. Future research on learning opportunities of multilingual children should address the heterogeneous nature of multilingual children either by using methods that are more suitable for smaller samples, by addressing only a subgroup of multilingual children with comparable background characteristics (e.g., home language, socioeconomic status, age of acquisition), or by using a larger sample. Third, the present study only focused on the individual learning opportunities of the focal children. This does not show the full picture, as a child will also be passively involved in many more interactions. For example, when a teacher is talking to another child in the same small group or when the teacher provides a plenary instruction during circle time. Therefore, future research should consider not only the individual child's experiences but also the general classroom 
interactions. Fourth, one of the main assets of this study is its ecologically valid approach to data collection. This asset, however, represents some drawbacks. The repeated filming, as well as teacher's knowledge of who the focal children were, might have invoked a Hawthorne effect, in which teachers might have changed their behavior because of the research context, rather than the children they were interacting with (Shadish et al. 2002).

The present study contributed to the current knowledge base by taking a person-oriented approach and by using micro-analytic, observational data. Typically, research on the topic of learning opportunities in early childhood education uses whole classroom observation and a variable-oriented approach. We conducted observations on the individual level, which allowed us to collect rich data across the year including micro-level interaction data. This way, we could capture the complexity of teacher-child interactions and engagement patterns of monolingual and multilingual children within one classroom.

In sum, the present study showed that children within the same classroom are exposed to different learning opportunities. The teacher-child interactions of individual children differ on the level of communication channel, complexity, and quantity. It is promising to see that multilingual children are exposed to the same quality of interaction as monolingual children. However, they do show lower levels of engagement across classroom settings compared to their monolingual classmates. The present study emphasizes the importance of studying the learning opportunities of monolingual and multilingual children to create equal learning opportunities for all children in early childhood education.

Acknowledgments We would like to acknowledge the support of all the students that assisted in data collection and the transcribing and coding of the data. We also wish to express our gratitude to all children and teachers that participated in this research.

Open Access This article is licensed under a Creative Commons Attribution 4.0 International License, which permits use, sharing, adaptation, distribution and reproduction in any medium or format, as long as you give appropriate credit to the original author(s) and the source, provide a link to the Creative Commons licence, and indicate if changes were made. The images or other third party material in this article are included in the article's Creative Commons licence, unless indicated otherwise in a credit line to the material. If material is not included in the article's Creative Commons licence and your intended use is not permitted by statutory regulation or exceeds the permitted use, you will need to obtain permission directly from the copyright holder. To view a copy of this licence, visit http://creativecommons.org/licenses/by/4.0/.

\section{References}

Aitken, R. C. (1969). Measurement of feelings using visual analogue scales. Proceedings of the Royal Society of Medicine, 62(10), 989-993.

Bergman, L., \& Trost, K. (2006). The person-oriented versus the variable-oriented approach: are they complementary, opposites, or exploring different worlds? Merrill-Palmer Quarterly, 52(3), 601-632. https:/doi. org/10.1353/mpq.2006.0023.

Bialystok, E., \& Feng, X. (2011). Language proficiency and its implications for monolingual and bilingual children. In A. Durgunoglu \& C. Goldenberg (Eds.), Language and literacy development in bilingual settings (pp. 121-138). New York, NY: Guilford Press.

Booren, L. M., Downer, J. T., \& Vitiello, V. E. (2012). Observations of children's interactions with teachers, peers, and tasks across preschool classroom activity settings. Early Education and Development, 23(4), 517538. https://doi.org/10.1080/10409289.2010.548767.

Bossong, L., \& Keller, H. (2018). Cross-cultural value mismatch in German day care institutions: perspectives of migrant parents and day care teachers. International Journal of Psychology, 53(2), 72-80. https://doi. org/10.1002/ijop.12559. 
Bratsch-Hines, M. E., Burchinal, M., Peisner-Feinberg, E., \& Franco, X. (2019). Frequency of instructional practices in rural prekindergartenclassrooms and associations with child language and literacy skills. Early Childhood Research Quarterly, 47, 74-88. https://doi.org/10.1016/J.ECRESQ.2018.10.001

Bronfenbrenner, U., \& Morris, P. (2007). The bioecological model of human development. In R.M. Lerner \& W. Damon (Eds.), Handbook of child psychology: vol 1, theoretical models of human development (6th ed., pp. 793-828). https://doi.org/10.1002/9780470147658.chpsy0114.

Cabell, S. Q., DeCoster, J., LoCasale-Crouch, J., Hamre, B. K., \& Pianta, R. C. (2013). Variation in the effectiveness of instructional interactions across preschool classroom settings and learning activities. Early Childhood Research Quarterly, 28(4), 820-830. https://doi.org/10.1016/j.ecresq.2013.07.007

CBS. (2013). Bevolking en huishoudens; viercijferige postcode, 1 januari 2012. Retrieved March 31, 2016, from https://statline.cbs.nl/Statweb/publication/?DM=SLNL\&PA=81922NED\&D1=0,63-65\&D2=0,15,515 ,2405,3612,3854-3884,4033,4121,4138,4162,4164,4168,4176,4208,4216,4219,4294,4352,4363,4444 $\& \mathrm{HDR}=\mathrm{T} \& \mathrm{STB}=\mathrm{G} 1 \& \mathrm{VW}=\mathrm{T}$

CBS. (2018). Jaarrapport Integratie 2018 [Year report integration 2018]. Centraal Bureau voor de Statistiek.

CBS. (2019). Leerlingen in (speciaal) basisonderwijs; migratieachtergrond, woonregio. Retrieved August 26, 2019, from https://opendata.cbs.nl/\#/CBS/nl/dataset/83295NED/table?ts=1566831822273

Chien, N. C., Howes, C., Burchinal, M., Pianta, R. C., Ritchie, S., Bryant, D., et al. (2010). Children's classroom engagement and school readiness gains in prekindergarten. Child Development, 81(5), 1534-1549. https://doi.org/10.1111/j.1467-8624.2010.01490.x.

Childers, J. B., \& Tomasello, M. (2002). Two-year-olds learn novel nouns, verbs, and conventional actions from massed or distributed exposures. Developmental Psychology, 38(6), 967-978. https://doi.org/10.1037/00121649.38.6.967.

Christ, T., Wang, X. C., \& Chiu, M. M. (2011). Using story dictation to support young children's vocabulary development: outcomes and process. Early Childhood Research Quarterly, 26(1), 30-41. https://doi. org/10.1016/J.ECRESQ.2010.06.002.

Cirino, P. T., Pollard-Durodola, S. D., Foorman, B. R., Carlson, C. D., \& Francis, D. J. (2007). Teacher characteristics, classroom instruction, and student literacy and language outcomes in bilingual kindergartners. The Elementary School Journal, 107(4), 341-364. https://doi.org/10.1086/516668.

Cummins, J. (1979). Linguistic interdependence and the educational development of bilingual children. Review of Educational Research, 49(2), 222-251. https://doi.org/10.3102/00346543049002222.

Daniels, M. (1997). Teacher enrichment of prekindergarten curriculum with sign language. Journal of Research in Childhood Education, 12(1), 27-33. https://doi.org/10.1080/02568549709594713.

De Temple, J. M. (2001). Parents and children reading books together. In D. K. Dickinson \& P. O. Tabors (Eds.), Beginning literacy with language (pp. 33-51). Baltimore, MD: Paul H. Brookes.

Dickinson, D. K., McCabe, A., \& Anastasopoulos, L. (2003). A framework for examining book reading in early childhood classrooms. In A. van Kleeck, S. Stahl, \& E. B. Bauer (Eds.), On reading books to children: parents and teachers (pp. 91-108). https://doi.org/10.4324/9781410607355.

Fredricks, J. A., Blumenfeld, P. C., \& Paris, A. H. (2004). School engagement: potential of the concept, state of the evidence. Review of Educational Research, 74(1), 59-109. https://doi.org/10.3102/00346543074001059.

Gillanders, C. (2007). An English-speaking prekindergarten teacher for young Latino children: implications of the teacher-child relationship on second language learning. Early Childhood Education Journal, 35(1), 4754. https://doi.org/10.1007/s10643-007-0163-x.

Goldin-Meadow, S. (2000). Beyond words: the importance of gesture to researchers and learners. Child Development, 71(1), 231-239. https://doi.org/10.1111/1467-8624.00138.

Goodwyn, S., \& Acredolo, L. (1998). Encouraging symbolic gestures: a new perspective on the relationship between gesture and speech. New Directions for Child Development, 79(Spring), 61-73. https://oi. org/10.1002/cd.23219987905.

Goodwyn, S., Acredolo, L., \& Brown, C. A. (2000). Impact of symbolic gesturing on early language development. Journal of Nonverbal Behavior, 24(2), 81-103. https://doi.org/10.1023/A:1006653828895.

Greenfield, P. M., Quiroz, B., \& Raeff, C. (2000). Cross-cultural conflict and harmony in the social construction of the child. New Directions for Child and Adolescent Development, 2000(87), 93-108. https://doi. org/10.1002/cd.23220008708.

Gregory, E. (1993). What counts as reading in the early years' classroom? British Journal of Educational Psychology, 63(2), 214-230. https://doi.org/10.1111/j.2044-8279.1993.tb01053.x.

Hamre, B. K., \& Pianta, R. C. (2007). Learning opportunities in preschool and early elementary classrooms. In R. C. Pianta, M. Cox, \& K. L. Snow (Eds.), School readiness and the transition to kindergarten in the era of accountability (pp. 49-83). Baltimore, MD: Paul H. Brookes.

Hickendorff, M., Edelsbrunner, P. A., McMullen, J., Schneider, M., \& Trezise, K. (2018). Informative tools for characterizing individual differences in learning: latent class, latent profile, and latent transition analysis. Learning and Individual Differences, 66, 4-15. https://doi.org/10.1016/J.LINDIF.2017.11.001. 
Hoff, E., \& Naigles, L. (2002). How children use input to acquire a lexicon. Child Development, 73(2), 418-433. https://doi.org/10.1111/1467-8624.00415.

Laevers, F. (1993). De Leuvense betrokkenheidsschaal voor kleuters. Handleiding bij de videomontage. [The Leuven engagement scale for kindergarteners. Manual for the video editing.]. Leuven: Centrum voor Ervaringsgericht Onderwijs.

Langeloo, A., Mascareño Lara, M., Deunk, M. I., Klitzing, N. F., \& Strijbos, J. W. (2019). A systematic review of teacher-child interactions with multilingual young children. Review of Educational Research, 89(4), 536568. https://doi.org/10.3102/0034654319855619.

Lara-Alecio, R., Tong, F., Irby, B. J., \& Mathes, P. (2009). Teachers' pedagogical differences during ESL block among bilingual and English-immersion kindergarten classrooms in a randomized trial study. Bilingual Research Journal, 32(1), 77-100. https://doi.org/10.1080/15235880902965938.

Leung, C. (1993). National curriculum: ESL in primary education in England. A classroom study. Language and Education, 7(3), 163-180. https://doi.org/10.1080/09500789309541357.

Mascareño, M., Snow, C. E., Deunk, M. I., \& Bosker, R. J. (2016). Language complexity during read-alouds and kindergartners' vocabulary and symbolic 10.1007/s10212-020-00487-0 understanding. Journal of Applied Developmental Psychology, 44, 39-51. https://doi.org/10.1016/j.appdev.2016.02.001

Mascareño, M., Deunk, M. I., Snow, C. E., \& Bosker, R. J. (2017). Read-alouds in kindergarten classrooms: a moment-by-moment approach to analyzing teacher-child interactions. European Early Childhood Education Research Journal, 25(1), 136-152. https://doi.org/10.1080/1350293X.2016.1266226

Massey, S. L., Pence, K. L., Justice, L. M., \& Bowles, R. P. (2008). Educators' use of cognitively challenging questions in economically disadvantaged preschool classroom contexts. Early Education and Development, 19(2), 340-360. https://doi.org/10.1080/10409280801964119.

Michaels, S., \& O’Connor, C. (2015). Conceptualizing talk moves as tools: professional development approaches for academically productive discussion. In L. B. Resnick, C. Asterhan, \& S. N. Clarke (Eds.), Socializing intelligence through talk (pp. 347-362). https://doi.org/10.3102/978-0-935302-43-1_27.

Muthén, L. K., \& Muthén, B. O. (1998). Mplus user's guide (8th ed.). Los Angeles, CĀ: Muthén \& Muthén.

Nassaji, H., \& Wells, G. (2000). What's the use of "triadic dialogue"?: An investigation of teacher-student interaction. Applied Linguistics, 21(3), 376-406.

Park, M.-H. (2014). Increasing English language learners' engagement in instruction through emotional scaffolding. Multicultural Education, 22(1), 20-29.

Ping, M. T. (2014). Group interactions in dialogic book reading activities as a language learning context in preschool. Learning, Culture and Social Interaction, 3(2), 146-158. https://doi.org/10.1016/j. lcsi.2014.03.001.

Razfar, A., \& Rumenapp, J. C. (2012). Language ideologies in English learner classrooms: critical reflections and the role of explicit awareness. Language Awareness, 21(4), 347-368. https://doi.org/10.1080 /09658416.2011.616591.

Rosborough, A. (2014). Gesture, meaning-making, and embodiment: second language learning in an elementary classroom. Journal of Pedagogy, 5(2), 227-250. https://doi.org/10.2478/jped-2014-0011.

Roth, W.-M. (2001). Gestures: their role in teaching and learning. Review of Educational Research, 71(3), 365392. https://doi.org/10.3102/00346543071003365.

Shadish, W. R., Cook, T. D., \& Campbell, D. T. (2002). Experimental and quasi-experimental designs dor generalized causal inference. Boston, NY: Houghton Mifflin Company.

Sullivan, B., Hegde, A. V., Ballard, S. M., \& Ticknor, A. S. (2015). Interactions and relationships between kindergarten teachers and English language learners. Early Child Development and Care, 185(3), 341-359. https://doi.org/10.1080/03004430.2014.919496.

Tenenbaum, H. R., \& Ruck, M. D. (2007). Are teachers' expectations different for racial minority than for European American students? A meta-analysis. Journal of Educational Psychology, 99(2), 253-273. https://doi.org/10.1037/0022-0663.99.2.253.

Tompkins, V., Zucker, T. A., Justice, L. M., \& Binici, S. (2013). Inferential talk during teacher-child interactions in small-group play. Early Childhood Research Quarterly, 28(2), 424-436. https://doi.org/10.1016/J. ECRESQ.2012.11.001.

van Kleeck, A., Vander Woude, J., \& Hammett, L. (2006). Fostering literal and inferential language skills in head start preschoolers with language impairment using scripted book-sharing discussions. American Journal of Speech-Language Pathology, 15(1), 85-95. https://doi.org/10.1044/1058-0360 2006/009.

Veenstra, R., \& Kuyper, H. (2004). Effective students and families: the importance of individual characteristics for achievement in high school. Educational Research and Evaluation, 10(1), 41-70. https://doi.org/10.1076 /edre.10.1.41.26302.

Verhoeven, L. T. (2000). Components in early second language reading and spelling. Scientific Studies of Reading, 4(4), 313-330. https://doi.org/10.1207/S1532799XSSR0404_4. 
Vine, E. W. (2006). "Hospital": a five-year-old Samoan boy's access to learning curriculum content in his New Zealand classroom. Language and Education, 20(3), 232-254. https://doi.org/10.1080 $/ 09500780608668725$.

Vitiello, V. E., Booren, L. M., Downer, J. T., \& Williford, A. P. (2012). Variation in children's classroom engagement throughout a day in preschool: relations to classroom and child factors. Early Childhood Research Quarterly, 27(2), 210-220. https://doi.org/10.1016/j.ecresq.2011.08.005.

Wasik, B., \& Bond, M. A. (2001). Beyond the pages of a book: interactive book reading and language development in preschool classrooms. Journal of Educational Psychology, 93(2), 243-250. https://oi. org/10.1037//0022-O663.93.2.243.

Wasik, B., Bond, M. A., \& Hindman, A. (2006). The effects of a language and literacy intervention on head start children and teachers. Journal of Educational Psychology, 98(1), 63-74. https://doi.org/10.1037/00220663.98.1.63.

Weizman, Z., \& Snow, C. E. (2001). Lexical input as related to children's vocabulary acquisition: effects of sophisticated exposure and support for meaning. Developmental Psychology, 37(2), 265-279. https://doi. org/10.1037/0012-1649.37.2.265.

Williford, A. P., Maier, M. F., Downer, J. T., Pianta, R. C., \& Howes, C. (2013). Understanding how children's engagement and teachers' interactions combine to predict school readiness. Journal of Applied Developmental Psychology, 34(6), 299-309. https://doi.org/10.1016/j.appdev.2013.05.002.

Zucker, T. A., Justice, L. M., Piasta, S. B., \& Kaderavek, J. N. (2010). Preschool teachers' literal and inferential questions and children's responses during whole-class shared reading. Early Childhood Research Quarterly, 25(1), 65-83. https://doi.org/10.1016/j.ecresq.2009.07.001.

Publisher's note Springer Nature remains neutral with regard to jurisdictional claims in published maps and institutional affiliations.

Annegien Langeloo. GION education/research, University of Groningen, Grote Rozenstraat 3, 9712 TG, Groningen, The Netherlands. E-mail: aglangeloo@gmail.com

Current themes of research:

Learning opportunities. Early childhood education. Multilingualism. Classroom interactions.

Most relevant publications in the field of Psychology of Education:

Langeloo, A., Deunk, M.I., Mascareño Lara, M., van Rooijen, M., \& Strijbos, J.W. (2019). Learning opportunities of monolingual and multilingual kindergarteners and their early literacy and executive functioning development. Early Education and Development. Advance online publication. https://doi.org/10.1080/ 10409289.2019.1697607.

Langeloo, A., Mascareño Lara, M., Deunk, M.I., Klitzing, N.F., \& Strijbos, J.W. (2019). A systematic review on teacher-child interactions with multilingual young children. Review of Educational Research, 89(4), 536568. https://doi.org/10.3102/0034654319855619.

Mayra Mascareño Lara. GION education/research, University of Groningen, Grote Rozenstraat 3, 9712 TG, Groningen, The Netherlands. E-mail: m.n.mascareno.lara@rug.nl

Current themes of research:

Learning opportunities. Classroom interactions. Classroom processes. Classroom quality. Child development. Language and literacy. Educational equity.

Most relevant publications in the field of Psychology of Education:

Langeloo, A., Mascareño Lara, M., Deunk, M.I., Klitzing, N.F., \& Strijbos, J.W. (2019). A systematic review on teacher-child interactions with multilingual young children. Review of Educational Research, 89(4), 536568. https://doi.org/10.3102/0034654319855619. 
Langeloo, A., Deunk, M.I., Mascareño Lara, M., van Rooijen, M., \& Strijbos, J.W. (2019). Learning opportunities of monolingual and multilingual kindergarteners and their early literacy and executive functioning development. Early Education and Development. Advance online publication. https://doi.org/10.1080/ 10409289.2019.1697607.

Mascareño Lara, M., Deunk, M. I., Snow, C. E., \& Bosker, R. J. (2017). Read-alouds in kindergarten classrooms: a moment-by-moment approach to analyzing teacher-child interactions. European Early Childhood Education Research Journal, 25(1), 136-152. https://doi.org/10.1080/1350293X.2016.1266226.

Mascareño Lara, M., Snow, C.E., Deunk, M.I., \& Bosker, R.J. (2016). Language complexity during read-alouds and kindergartners' vocabulary and symbolic understanding. Journal of Applied Developmental Psychology, 44 (May-June), 39-51. https://doi.org/10.1016/j.appdev.2016.02.001.

Marjolein I. Deunk. GION education/research, University of Groningen, Grote Rozenstraat 3, 9712 TG, Groningen, The Netherlands. E-mail: m.i.deunk@rug.nl

\section{Current themes of research:}

Learning opportunities. Classroom interactions. Language and literacy development. Cultural diversity and inclusion. (Pre-service) Teacher professional development.

Most relevant publications in the field of Psychology of Education:

Langeloo, A., Deunk, M.I., Mascareño Lara, M., van Rooijen, M., \& Strijbos, J.W. (2019). Learning opportunities of monolingual and multilingual kindergarteners and their early literacy and executive functioning development. Early Education and Development. Advance online publication. https://doi.org/10.1080/ 10409289.2019.1697607.

Langeloo, A., Mascareño Lara, M., Deunk, M.I., Klitzing, N.F., \& Strijbos, J.W. (2019). A systematic review on teacher-child interactions with multilingual young children. Review of Educational Research, 89(4), 536568. https://doi.org/10.3102/0034654319855619.

ter Beek, M., Opdenakker, M-C., Deunk, M.I., \& Strijbos, J-W. (2019). Teaching reading strategies in history lessons: a micro-level analysis of professional development training and its practical challenges. Studies in Educational Evaluation, 63, 26-40. https://doi.org/10.1016/j.stueduc.2019.07.003.

Mascareño Lara, M., Deunk, M.I., Snow, C.E., \& Bosker, R.J. (2017). Read-alouds in kindergarten classrooms: a moment-by-moment approach to analyzing teacher-child interactions. European Early Childhood Education Research Journal, 25(1), 136-152. https://doi.org/10.1080/1350293X.2016.1266226.

Deunk, M.I., Berenst, J., \& de Glopper, C. (2013). Home-school book sharing comes in many forms: a microanalysis of teacher-child interaction during the activity of borrowing a school book. Journal of Early Childhood Literacy, 13(2), 242-270. https://doi.org/10.1177/1468798411430103

Jennifer LoCasale-Crouch. Center for Advanced Study of Teaching and Learning, University of Virginia, 405 Emmet Street South, Office 244, Charlottesville, VA 22904, USA. E-mail: j13d@virginia.edu

\section{Current themes of research:}

Adult behavior and beliefs and children's development. Classroom processes that support development. Professional development.

Most relevant publications in the field of Psychology of Education:

Hu, B., Song, Z., Wang, S., \& LoCasale-Crouch, J. (2019). Global quality profiles in Chinese early care classrooms: evidence from the Shandong Province. Children and Youth Services Review, 101, 157-164. https://doi.org/10.1016/j.childyouth.2019.03.056.

Roberts, A., LoCasale-Crouch, J., Hamre, B., \& Jamil, F. (2019). Preschool teachers' self-efficacy, burnout, and stress in online professional development: a mixed methods approach to understand change. Journal of Early Childhood Teacher Education. https://doi.org/10.1080/10901027.2019.1638851.

LoCasale-Crouch, J., Williford, A., Whittaker, J., DeCoster, J., \& Alamos, P. (2018). Does fidelity of implementation account for changes in teacher-child interactions in a randomized control trial of Banking Time? The Journal of Research on Educational Effectiveness, 11(1), 35-55. https://doi.org/10.1080/ 19345747.2017.1329365. 
Jan-Willem Strijbos. GION education/research, University of Groningen, Grote Rozenstraat 3, 9712 TG, Groningen, The Netherlands. E-mail: j.w.strijbos@rug.nl

Current themes of research:

Assessment and feedback. Technology-enhanced learning (TEL). (Computer-supported) collaborative learning (CS)CL. Peer assessment. Peer feedback. Feedback dialogues. Communities of learners/communities of practice. Instructional design. Analysis methods for (CS)CL. Content analysis of discourse.

Most relevant publications in the field of Psychology of Education:

Langeloo, A., Deunk, M.I., Mascareño Lara, M., van Rooijen, M., \& Strijbos, J.W. (2019). Learning opportunities of monolingual and multilingual kindergarteners and their early literacy and executive functioning development. Early Education and Development. Advance online publication. https://doi.org/10.1080/ 10409289.2019.1697607.

Langeloo, A., Mascareño Lara, M., Deunk, M.I., Klitzing, N.F., \& Strijbos, J.W. (2019). A systematic review on teacher-child interactions with multilingual young children. Review of Educational Research, 89(4), 536568. https://doi.org/10.3102/0034654319855619.

Strijbos, J.W., \& Stahl, G. (2007). Methodological issues in developing a multi-dimensional coding procedure for small group chat communication. Learning and Instruction, 17(4), 394 404. https://doi.org/10.1016/ j.learninstruc.2007.03.005.

Strijbos, J.W., Martens, R.L., Prins, F.J., \& Jochems, W.M.G. (2006). Content analysis: what are they talking about? Computers and Education, 46(1), 29-48. https://doi.org/10.1016/j.compedu.2005.04.002

\section{Affiliations}

\section{Annegien Langeloo ${ }^{1} \cdot$ Mayra Mascareño Lara ${ }^{1} \cdot$ Marjolein I. Deunk ${ }^{1} \cdot$ Jennifer LoCasale-Crouch $^{2}$ • Jan-Willem Strijbos ${ }^{1}$}

Mayra Mascareño Lara

m.n.mascareno.lara@rug.nl

Marjolein I. Deunk

m.i.deunk@rug.nl

Jennifer LoCasale-Crouch

j13d@virginia.edu

Jan-Willem Strijbos

j.w.strijbos@rug.nl

1 GION education/research, University of Groningen, Grote Rozenstraat 3, 9712 TG Groningen, The Netherlands

2 Center for Advanced Study of Teaching and Learning, University of Virginia, 405 Emmet Street South, Office 244, Charlottesville, VA 22904, USA 